\title{
Numerical Investigation of Mechanical Durability in Polymer Electrolyte Membrane Fuel Cells
}

\author{
Ahmet Kusoglu \\ University of Delaware \\ Michael H. Santare \\ University of Delaware
}

Anette M. Karlsson

Cleveland State University, a.karlsson@csuohio.edu

Simon Cleghorn

Gore Fuel Cell Technologies

William B. Johnson

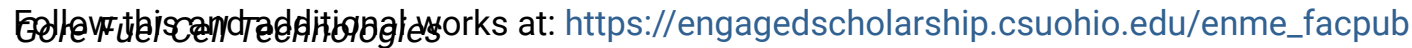

Part of the Mechanical Engineering Commons

How does access to this work benefit you? Let us know!

\section{Publisher's Statement}

(C) The Electrochemical Society, Inc. [2010]. All rights reserved. Except as provided under U.S. copyright law, this work may not be reproduced, resold, distributed, or modified without the express permission of The Electrochemical Society (ECS). The archival version of this work was published in [J. Electrochem. Soc. 2010 volume 157, issue 5, B705-B713].

\section{Original Citation}

Kusoglu, A., Santare, M. H., Karlsson, A. M., 2010, "Numerical Investigation of Mechanical Durability in Polymer Electrolyte Membrane Fuel Cells," Journal of the Electrochemical Society, 157(5) pp. B705-B713.

This Article is brought to you for free and open access by the Mechanical Engineering Department at EngagedScholarship@CSU. It has been accepted for inclusion in Mechanical Engineering Faculty Publications by an authorized administrator of EngagedScholarship@CSU. For more information, please contact library.es@csuohio.edu. 


\section{Numerical Investigation of Mechanical Durability in Polymer Electrolyte Membrane Fuel Cells}

Ahmet Kusoglu, Michael H. Santare, Anette M. Karlsson, Simon Cleghorn and William B. Johnson

J. Electrochem. Soc. 2010, Volume 157, Issue 5, Pages B705-B713.

doi: $10.1149 / 1.3328496$

Email alerting Receive free email alerts when new articles cite this article - sign up in the box at the service top right corner of the article or click here

To subscribe to Journal of The Electrochemical Society go to:

http://jes.ecsdl.org/subscriptions

(C) 2010 ECS - The Electrochemical Society 


\title{
Numerical Investigation of Mechanical Durability in Polymer Electrolyte Membrane Fuel Cells
}

\author{
Ahmet Kusoglu, ${ }^{\text {a,* }}$ Michael H. Santare, ${ }^{\text {a,z }}$ Anette M. Karlsson, ${ }^{\text {a }}$ Simon Cleghorn, ${ }^{\text {b }}$ \\ and William B. Johnson ${ }^{\mathrm{b}, * *}$
}

${ }^{a}$ Department of Mechanical Engineering, University of Delaware, Newark, Delaware 19716, USA

${ }^{b}$ Gore Fuel Cell Technologies, Elkton, Maryland 21922, USA

\begin{abstract}
The relationship between the mechanical behavior and water transport in the membrane electrode assembly (MEA) is numerically investigated. Swelling plays a key role in the mechanical response of the MEA during fuel cell operation because swelling can be directly linked to the development of stresses. Thus, in the model introduced here, the stresses and the water distribution are coupled. Two membranes are studied: unreinforced perfluorosulfonic acid (PFSA) and an experimental reinforced composite membrane. The results suggest that open-circuit voltage operations lead to a uniform distribution of stresses and plastic deformation, whereas under current-load operation, the stresses and the plastic deformation are generally lower and localized at the cathode side of the MEA. For the experimental reinforced membrane investigated, the in-plane swelling and, consequently, the stresses and plastic deformation are lower than in an unreinforced PFSA membrane. This reduction is a favorable outcome for improving durability. The model also suggests that the mechanical constraints due to the clamping of the cell may limit the swelling of the membrane and consequently change the water distribution.

(C) 2010 The Electrochemical Society. [DOI: 10.1149/1.3328496] All rights reserved.
\end{abstract}

Manuscript submitted September 3, 2009; revised manuscript received January 26, 2010. Published April 2, 2010.

Proton exchange membrane fuel cells (PEMFCs) are a potential alternative power source for transportation and stationary applications because of their ability to provide a clean and efficient way of generating electricity. However, premature failure of the cell components has limited the commercialization of PEMFCs. The U.S. Department of Energy has set the target for durability at high operating temperatures $\left(>80^{\circ} \mathrm{C}\right)$ to $5000 \mathrm{~h}$ by $2015 .{ }^{1}$

Fuel cell life is primarily driven by chemical and mechanical degradation and damage to the membrane, though the reduction of catalyst activity during operation is an important secondary factor. The membrane degradation rate of perfluorinated polymer membranes, as measured by the amount of fluoride in the product water or so-called fluoride release rate, is found higher under elevated temperature operations $\left(>90^{\circ} \mathrm{C}\right),{ }^{2-4}$ high pressure, ${ }^{3}$ and low humidity operating conditions. ${ }^{2-5}$ The slow decay in the voltage during open-circuit voltage (OCV) operation can also be associated with uniform membrane thinning. A higher decay during an extended OCV hold results from membrane thinning or pinhole formation between the electrodes and accelerates the hydrogen crossover, causing a drop in OCV. ${ }^{2,6,7} \mathrm{OCV}$ hold testing is an aggressive test of the chemical durability of the membrane because the concentration of reactive ion species such as peroxyl and hydroxyl ions is higher at higher potentials. However, OCV hold testing uses fixed humidity conditions, so the varying mechanical stresses induced from swelling and shrinking of the membrane are absent. In a real operating cell, there are both chemical degradation from reactive species and mechanical degradation from the varying stresses. The mechanical stresses arise from swelling and shrinking as the varying load on the cell drives the potential into conditions that produce large amounts of water at low potential and small amounts of water at high potential. The chemical and mechanical degradation can be coupled as cracks form due to mechanical stresses and open new surfaces for a chemical attack. Because microstructural changes and cracks are observed in membrane electrode assemblies (MEAs) after cell operation, ${ }^{8-12}$ stresses induced during hydration-dehydration cycles are believed to be responsible for the degradation of the membrane in the form of crack formation and propagation, ${ }^{11,13}$ membrane thinning (especially at the cathode side ${ }^{14}$ ), pinhole formation, or tearing through-the-thickness of the membrane. ${ }^{11}$ But existing data seem to indicate that the chemical attack is more severe than either the me-

\footnotetext{
* Electrochemical Society Student Member.

** Electrochemical Society Active Member.

z E-mail: santare@udel.edu
}

chanical stresses alone or those from coupled mechanical/chemical degradation. ${ }^{6,8}$ Evidence for this assertion comes from membrane lifetimes that are reported to be longer under load than under OCV hold testing. ${ }^{6,8}$ Furthermore, relative humidity $(\mathrm{RH})$ cycling tests in nitrogen yield mechanical stresses due to wet/dry hydrationdehydration cycles, which cause membrane failure. ${ }^{2,8,15}$ Nevertheless, membranes were shown to last much longer under RH cycle testing than under OCV hold testing, at least for today's advanced polymer membranes. ${ }^{2,8,15}$ A detailed understanding of the mechanical stresses and their effects are essential for designing and testing new membranes.

Swelling of the membrane due to humidity changes during cell operation reduces the cell performance (in OCV). ${ }^{1,15,16}$ We have previously shown that swelling is a key parameter for stresses developed in the membrane. ${ }^{13,17-19}$ Large in-plane compressive stresses are developed in the membrane during the hydration (swelling) of the membrane due to the constraints in the cell. These stresses can cause plastic (permanent) deformation of the membrane, resulting in tensile residual stresses when the membrane shrinks upon dehydration. ${ }^{13,19}$

We have previously conducted numerical investigations into the effects of cell design and clamping loads, ${ }^{13,17}$ membrane thickness, ${ }^{17-19}$ membrane mechanical properties, ${ }^{13,17-19}$ and swelling anisotropy ${ }^{18,19}$ on the stresses and mechanical response of the proton exchange membrane (PEM). Similar results were obtained later along the surface of the MEA by Solasi et al. ${ }^{20}$ We have shown that low in-plane swelling strains result in lower stresses in the membrane, which is desirable because it potentially prevents the stresses from reaching the yield limit and inducing plastic deformation. ${ }^{18,19}$ These findings agreed with the test results of the reinforced GORESELECT membrane, ${ }^{\mathrm{c}}$ which swells less in-plane and lasts longer than unreinforced PFSA membranes. ${ }^{6,821-23}$ These studies suggest that dimensional stability and mechanical properties govern the mechanical failure mechanisms and ultimately affect the lifetime. ${ }^{6,8,21,23,24}$ Even though the effect of swelling on the mechanical behavior of fuel cell membranes is well documented, it remains to be established how the stresses and swelling (or water uptake) affect each other.

In this work, we investigate the relationship between stresses and water uptake in a PEM by developing a new modeling scheme in 
(A) Unit Cell

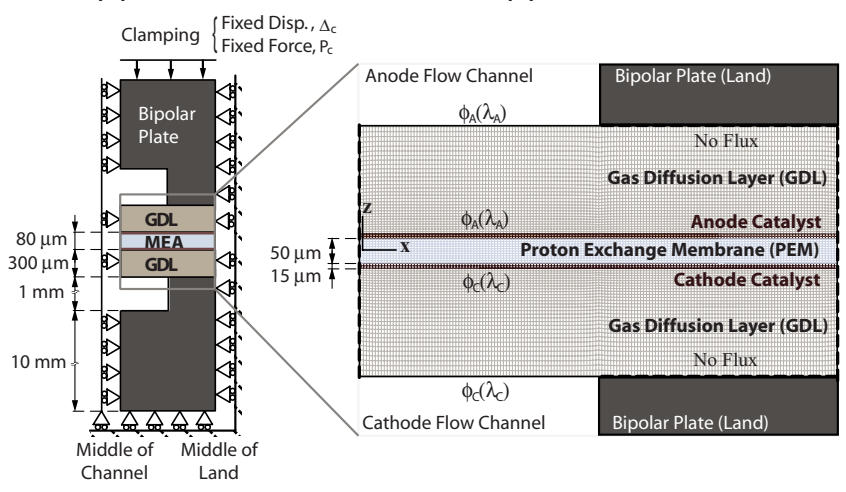

Figure 1. (Color online) (a) Unit cell developed for the numerical model showing the mechanical boundary conditions and (b) the detailed finite element model of the MEA and GDL shown with hygrothermal boundary conditions.

which the swelling-induced stresses and the water uptake through diffusion are coupled and solved simultaneously. Two membranes are investigated: (i) PFSA membrane of 1100 equivalent weight (EW) and (ii) experimental composite membrane of PFSA-based ionomer with microporous expanded PTFE reinforcement (R-PFSA) provided by W.L. Gore and Associates. As is the case with any such model, many parameters such as geometrical features and material properties must be assigned for numerical results to be generated. It is not our intention to model any particular fuel cell but instead to show the methodology and how it can be used to study any such system. Therefore, parameters are selected to study variations in membrane response in a hypothetical fuel cell system. We specifically investigate how the mechanical properties of the cell components, along with cell operating conditions, affect the water uptake and deformation behavior of the MEA.

\section{Model Definition}

Geometry. - The numerical model consists of a two-dimensional unit cell (Fig. 1), which is simulated using the commercial finite element package ABAQUS. ${ }^{25}$ To this end, we modified the models from our previous work. ${ }^{13,19}$ The geometry of the model, including the boundary conditions, is depicted in Fig. 1. To simulate the clamping of the fuel cell stack, the top surface of the bipolar plate is subjected to either $(i)$ fixed clamping pressure $P_{\mathrm{c}}$ or (ii) fixed clamping displacement $\Delta_{\mathrm{c}}$ [corresponding to the displacement of the colddry $\left(25^{\circ} \mathrm{C}\right.$ at $\left.30 \% \mathrm{RH}\right)$ cell under $P_{\mathrm{c}}=1 \mathrm{MPa}$. Symmetric boundary conditions for displacement are used at the bottom edge of the bipolar plate and on the right end of the unit cell, i.e., middle of the land (midland). To ensure the periodicity of the unit cell, all nodes are constrained to have uniform displacement at the left end of the cell, i.e., at the middle of the gas flow channels (midchannel). All interfaces are assumed to be perfectly bonded. Eight-node, reduced integration coupled temperature-displacement plane strain elements (CPEG8RT) are used for the simulations. ${ }^{25}$ The model consists of 17,798 elements and 42,414 nodes.

Distribution of the water volume fraction in the unit cell is numerically determined for selected boundary conditions, which correspond to the desired simulated cell operating condition (e.g., temperature, inlet gas humidity, and current density). The water absorption (and, consequently, the swelling) is assumed to take place only through the domain enclosing the MEA and the gas diffusion layer (GDL). Symmetry boundary conditions for water diffusion are used at the left and right edges of the MEA and GDL (Fig. 1) due to the periodicity of the cell, assuming a uniform distribution of water along the MEA. This would correspond to a counterflow cell configuration (i.e., anode/cathode inlet are located at the opposite sides of the cell) ${ }^{26}$ Because in an operating fuel cell, the water content varies along the channels, unit cells at various locations can be investigated by adjusting the water content boundary conditions to simulate the specific location of interest.

Assumptions.- The numerical model is developed based on the following assumptions:

i. The MEA is modeled as a three-layer material consisting of a membrane coated with catalyst layers. Although the membrane is allowed to swell in the presence of water, the electrodes do not swell. ${ }^{\mathrm{d}}$ None of the other components swell in the presence of water.

ii. The constitutive response for the membrane and the catalyst layers is linear-elastic followed by plastic response with isotropic hardening. The GDL and bipolar plates exhibit linear-elastic constitutive response.

iii. The mechanical properties and thermal expansion are isotropic and time-independent for all components. However, the model is capable of solving time-dependent behavior if the material properties are implemented as a function of time.

iv. The material properties and the diffusion coefficient for the MEA are incorporated into the model as functions of water content and temperature.

v. Steady-state, isothermal cell operation is simulated. The temperature throughout the cell is equal to the cell operating temperature $T_{\text {cell }}$, which is taken to be $85^{\circ} \mathrm{C}$.

vi. The EW of the membrane remains constant during the cell operation, ${ }^{14,27}$ and the sorption-desorption cycles are reversible.

Constitutive relations. - In the model, the $x$ - and $z$-axes correspond to the in-plane and out-of-plane (through-the-thickness) directions, respectively. Generalized plane strain is imposed in the third (y)-direction

$$
\varepsilon_{x y}=\varepsilon_{y x}=\varepsilon_{y z}=\varepsilon_{z y}=0 \text { and } \varepsilon_{y y}=\text { const }
$$

The elastic portion of the constitutive response is given by the linear Hooke's law, for which the stress tensor $\sigma_{i j}$ is

$$
\sigma_{i j}=\frac{E}{(1+v)(1-2 v)}\left[\nu \varepsilon_{\mathrm{V}}^{\mathrm{el}} \delta_{i j}+(1-2 v) \varepsilon_{i j}^{\mathrm{el}}\right]
$$

where $\varepsilon_{\mathrm{V}}^{\mathrm{el}}=\varepsilon_{x x}+\varepsilon_{y y}+\varepsilon_{z z}, v$ is Poisson's ratio, $\delta_{i j}$ is the Kronecker delta defined as

$$
\delta_{i j}= \begin{cases}1 & \text { if } i=j \\ 0 & \text { if } i \neq j\end{cases}
$$

and $E$ is Young's modulus. Here, Young's modulus is defined as a function of water content and temperature for the membrane and electrodes, i.e., $E=E\left(\phi_{\mathrm{w}}, T\right)$, and is assumed to be constant for the GDL and the bipolar plates.

To model the plastic constitutive response, we adopt the Mises yield criterion $\left(J_{2} \text {-flow theory }\right)^{29}$ with the rate-independent flow function $f$

$$
f\left(\sigma_{i j}, \varepsilon^{\mathrm{pl}}\right)=\sqrt{\frac{3}{2} S_{i j} S_{i j}}-\sigma^{Y}\left(\bar{\varepsilon}^{\mathrm{pl}}, \phi_{\mathrm{w}}, T\right)
$$

where $S_{i j}$ are the components of the deviatoric stress tensor defined by

$$
S_{i j}=\sigma_{i j}-\frac{1}{3}\left(\sigma_{x x}+\sigma_{y y}+\sigma_{z z}\right) \delta_{i j}
$$

where $\sigma_{i j}$ are the components of the true stress tensor. Thus, according to the Mises yield criterion, plastic deformation does not occur under hydrostatic stress. Furthermore, in Eq. $4, \sigma^{Y}\left(\bar{\varepsilon}^{\mathrm{pl}}, \phi_{\mathrm{w}}, T\right)$ is the yield strength of the material defined as a function of water volume

\footnotetext{
${ }^{\mathrm{d}}$ Although we do not have detailed data on the swelling of the electrodes, our investigations suggest that electrode swelling is significantly lower than the swelling in the membrane. In addition, model results indicate that electrode swelling does not affect the overall water transport or the stresses in the membrane. However, an assumption of swelling of the electrode increases the compressive stresses in the electrodes.
} 
fraction, temperature, and equivalent plastic strain $\bar{\varepsilon}^{\mathrm{pl}}$. Equivalent plastic strain is a measure of the current plastic strain during inelastic (permanent) deformation and is defined as

$$
\bar{\varepsilon}^{\mathrm{pl}}=\int \sqrt{\frac{2}{3} d \varepsilon_{i j}^{\mathrm{pl}} d \varepsilon_{i j}^{\mathrm{pl}}}
$$

where $d \varepsilon_{i j}^{\mathrm{pl}}$ are the increments of the plastic strain tensor. When the yield surface expands, the equivalent plastic strain increases and the material undergoes isotropic hardening. Accordingly, the flow function given by Eq. 4 changes in response to the current state of stress and the current plastic strain. ${ }^{29}$

The material exhibits plastic deformation with hardening when $f=0$ (Eq. 4). According to the Mises flow theory, the increments of the plastic strain are determined from the deviatoric stress tensor and yield strength (i.e., hardening curve) through the relation ${ }^{29}$

$$
d \varepsilon_{i j}^{\mathrm{pl}}=d \bar{\varepsilon}^{\mathrm{pl}} \frac{3}{2 \sigma^{Y}} S_{i j} \quad \text { if } f=0
$$

Details pertaining to the theory of elastoplasticity as applied to PEMFC simulations can be found in our previous study. ${ }^{1}$

The material properties for the bipolar plates are set to that of commercial graphite with a modulus of $10 \mathrm{GPa}$, and for the GDL, the properties are obtained from an SGL commercial carbon paper. ${ }^{30}$ Our preliminary tensile tests for the SGL carbon paper indicate a temperature-independent linear-elastic behavior for the strain range of interest here with an elastic modulus of $3 \mathrm{GPa}$. For the sake of simplicity, the GDL is assumed to be isotropic, even though there is literature indicating that it exhibits an anisotropic behavior. ${ }^{31}$ Anisotropic moduli can easily be included in the model. For comparison between different PEM behaviors, two different materials are considered: unreinforced PFSA and an experimental reinforced composite membrane. In the first case, the mechanical properties of a PFSA membrane of $1100 \mathrm{EW}$ are used. ${ }^{19}$ Young's modulus of the PFSA membrane is characterized as a function of temperature and water volume fraction based on the experimental data of Tang et al. ${ }^{32}$ and the corresponding mechanical model. ${ }^{33}$ To accurately capture the nonlinear large-strain constitutive behavior of the membrane, experimental true stress-true strain curves ${ }^{32,34}$ are incorporated into the numerical model. ${ }^{\mathrm{e}}$ Stress-strain curves and Young's modulus of the PFSA membrane swollen in liquid water are adopted from our recent study. ${ }^{35}$ The electrode properties are obtained as functions of temperature and water content in a similar fashion from our ongoing research. Experimental data for Young's modulus and the stressstrain behavior of reinforced composite membrane were obtained in a similar manner from our previous work. ${ }^{18}$

Characterization of swelling and strain components.- Components of the incremental strain tensor $d \varepsilon_{i j}$ can be decomposed into increments of elastic strain $d \varepsilon_{i j}^{\mathrm{el}}$, plastic strain $d \varepsilon_{i j}^{\mathrm{pl}}$, thermal strain $d \varepsilon_{i j}^{\text {th }}$, and swelling strain induced due to water absorption $d \varepsilon_{i j}^{\mathrm{sw}}$

$$
d \varepsilon_{i j}=d \varepsilon_{i j}^{\mathrm{el}}+d \varepsilon_{i j}^{\mathrm{pl}}+d \varepsilon_{i j}^{\mathrm{th}}+d \varepsilon_{i j}^{\mathrm{sw}}
$$

For isotropic thermal strains, an increment in strain due to a change in the temperature $T$, with respect to the temperature at the beginning of the increment $T_{0}$, can be written as

$$
d \varepsilon_{i j}^{\text {th }}=\alpha \delta_{i j} d T=\alpha \delta_{i j}\left(T-T_{0}\right)
$$

where $\alpha$ is the linear coefficient of thermal expansion $\left(C^{-1}\right)$ and $\delta_{i j}$ is defined in Eq. 3. The change in the volume of the membrane during sorption/desorption is used to derive the swelling strain increments through the introduction of an anisotropy ratio of the swelling $\xi_{i}$, which satisfies the condition $\xi_{x}+\xi_{y}+\xi_{z}=1$. The relationship between the volumetric water uptake and the dimensional changes due to swelling is then

\footnotetext{
' The experimental data are adapted to the numerical model by converting humidity values, at which the tensile tests were conducted, into the water volume fraction $\phi_{\mathrm{w}}$
}

$$
d \varepsilon_{i j}^{\mathrm{sw}}=\xi_{i} \ln \frac{V_{\mathrm{p}}+d V}{V_{\mathrm{p}}} \delta_{i j}=\xi_{i} \ln \left(\frac{1}{\phi_{\mathrm{p}}}\right) \delta_{i j}
$$

where $V_{\mathrm{p}}$ is the volume of the polymer membrane at the beginning of the increment, $d V$ is the volume of the absorbed/desorbed water, and $d \phi_{\mathrm{p}}$ (or $1-d \phi_{\mathrm{w}}$ ) is the change in the polymer (or water) volume fraction with respect to the initial dry state. Here, we have used the true strain ${ }^{\mathrm{f}}$ to represent the swelling-induced strain due to the large deformations involved. According to Eq. 10, swelling strains are positive during sorption $\left(d \phi_{\mathrm{w}}, d V>0\right)$ and negative during desorption $\left(d \phi_{\mathrm{w}}, d V<0\right)$. For the case of an isotropically swollen PFSA membrane, it holds that $\xi_{i=x, y, z}=1 / 3$. The increment in the swelling strain (Eq. 10), due to a change in the polymer volume fraction $d \phi_{\mathrm{p}}=\phi_{\mathrm{p}}^{\text {current }}-\phi_{\mathrm{p}}^{\text {previous }}$ between any two subsequent time increments, is implemented in the following discrete form

$$
d \varepsilon_{\text {isotropic }}^{\mathrm{sw}}=\frac{1}{3} \ln \left(\frac{1}{\phi_{\mathrm{p}}^{\text {current }}}\right)-\frac{1}{3} \ln \left(\frac{1}{\phi_{\mathrm{p}}^{\text {previous }}}\right)
$$

Studies have shown that the reinforced membrane (R-PFSA) exhibits highly anisotropic swelling ${ }^{21,24}$ but that its total water uptake is similar to that of the unreinforced PFSA membrane. ${ }^{36}$ In the reinforced membranes, a 10-fold increase in swelling strain is measured in the out-of-plane direction compared to the in-plane direction, ${ }^{18}$ corresponding to anisotropy ratios of $\xi_{x}=\xi_{y}=1 / 12$ and $\xi_{z}$ $=10 / 12$. (For these ratios, Eq. 10 gives $d \varepsilon_{z z}^{\mathrm{sw}}=10 d \varepsilon_{x x}^{\mathrm{sw}}=10 d \varepsilon_{y y}^{\mathrm{sw}}$.) The water content in the PFSA-based membranes, $\lambda$, is the number of water molecules attached to each sulfonic acid $\left(\mathrm{SO}_{3}^{-}\right)$group. By definition, the water volume fraction can be determined from the water content

$$
\phi_{\mathrm{w}}=\frac{18 \lambda}{\mathrm{EW} / \rho_{\mathrm{p}}+18 \lambda}
$$

where EW is the equivalent weight and $\rho_{\mathrm{p}}$ is the density of the dry polymer membrane. We determine the average water content in the PFSA membrane for a given water activity $a($ or $\mathrm{RH})$ at $25^{\circ} \mathrm{C}$ from expressions given in the literature. ${ }^{37,38}$ We also use Eq. 12 for the reinforced membrane because the total water uptake is similar to that of the PFSA membrane. ${ }^{36}$ The reference state is assumed to be $T_{0}=25^{\circ} \mathrm{C}$ and $\lambda=2$, at which $\varepsilon_{i j}^{\text {th }}=\varepsilon_{i j}^{\mathrm{sw}}=0$. For simplicity, we assume that the relationship between the water content $\lambda$ and humidity does not change with temperature.

However, even given this assumption, the swelling strain at a given humidity $\varepsilon_{i j}^{\text {sw }}$ increases with increasing temperature. ${ }^{32,39}$ Consequently, we implement the temperature effect directly into the swelling strains. The experimental data of Tang et al. ${ }^{32}$ for the swelling strains as a function of water content for PFSA membranes are depicted with markers in Fig. 2. The results suggest that the swelling strain increases with increasing temperature for a given water content. This increase is more than what would be expected from thermal strains alone because the coefficient of thermal expansion of the PFSA membranes is very low $\left(\sim 10^{-3} \mathrm{~K}^{-1}\right){ }^{40}$ To incorporate the temperature effect into the model, we empirically modify Eq. 10 to

$$
d \varepsilon_{\text {isotropic }}^{\mathrm{sw}}=\frac{1}{3}\left(\frac{T+273}{T_{0}+273}\right) \ln \left(\frac{1}{\phi_{\mathrm{p}}}\right)
$$

which demonstrates a good fit with the experimental data when plotted with respect to the dry state $\left(\lambda_{0}=2\right)$ (Fig. 2).

Water transport.- In this study, we use the empirical diffusion coefficient for water in the PFSA membrane, $D_{\mathrm{w}, \mathrm{PFSA}}\left(\mathrm{cm}^{2} / \mathrm{s}\right)$, adopted from Ref. 41

\footnotetext{
${ }^{\mathrm{f}}$ True strain is defined as the natural logarithm of the ratio of the deformed length to the initial, undeformed length.
} 


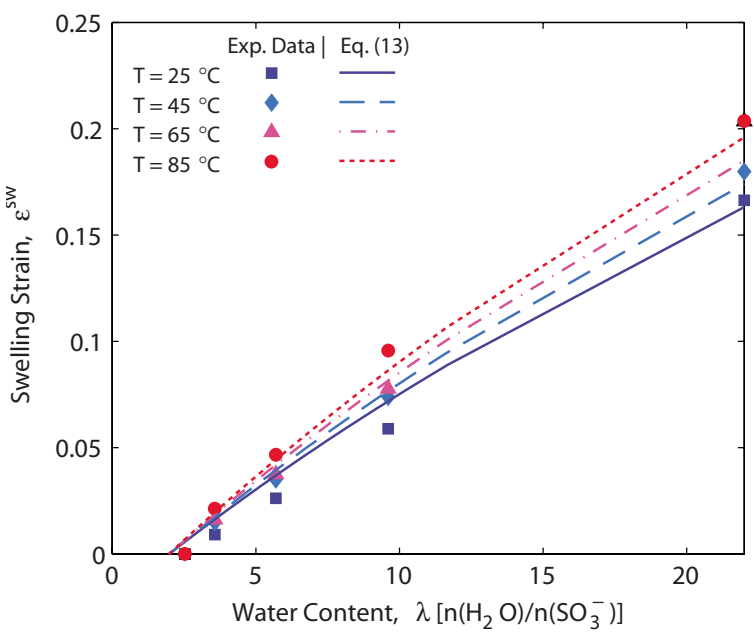

Figure 2. (Color online) Predictions of Eq. 13 for the swelling strain of the PFSA membrane as a function of water content and temperature compared with the measured values of Tang et al. ${ }^{32}$

$$
D_{\mathrm{w}, \mathrm{PFSA}}=1.8 \times 10^{-5} \phi_{\mathrm{w}} \exp \left[2406\left(\frac{1}{303}-\frac{1}{T+273}\right)\right]
$$

Similarly, the diffusion coefficient for water in the reinforced membrane (R-PFSA), $D_{\mathrm{w}, \mathrm{R}-\mathrm{PFSA}}$, can be obtained through our preliminary experimental observations

$$
D_{\mathrm{w}, \mathrm{R}-\mathrm{PFSA}}=0.9 \times 10^{-5} \exp \left[2625\left(\frac{1}{353}-\frac{1}{T+273}\right)\right]
$$

From these equations, the diffusion coefficient for the reinforced PFSA membrane is approximately half of that for the unreinforced PFSA membranes. This agrees with the values used for the GORESELECT membranes in Ref. 42. To adjust for the porous structure of the GDL, the Bruggemann correction ${ }^{43,44}$ is used to determine the diffusion coefficient for water in the GDL. Thus, $D_{\mathrm{w}, \mathrm{GDL}}$ $=\phi_{\text {pore,GDL }}^{1.5} D_{\mathrm{w}}$, where the pore volume fraction is $\phi_{\text {pore, GDL }}=0.80$ for the SGL carbon paper ${ }^{30}$ and $D_{\mathrm{w}}$ is the self-diffusion coefficient of water. (The effects of varying this correction factor are explored in the Results and Discussion section.)

In an operating fuel cell, the water profile through the MEA is determined through the interplay of the electro-osmotic drag of water molecules from the anode to the cathode and the diffusion of water due to the concentration difference over the membrane. Our model presently considers only the diffusion-dominated transport to determine the water profile. This approach should provide satisfactory results for water distribution under OCV (i.e., zero current density) operation. However, to simulate the cell operation under current load, the water content boundary conditions can be modified to reflect the changes in the water gradient due to the electro-osmotic drag. To provide values for these boundary conditions, we refer to the investigations in the literature on the in situ water profiles in the MEA. The numerical results ${ }^{37,43,45-47}$ and experimental observations $^{48,49}$ suggest a constant water content of $\lambda=14-16$ at the cathode side and a decreasing water content at the anode side with increasing current density due to electro-osmotic drag (anode dry-out). If no current is drawn from the cell, $\lambda$ is approximately uniform from anode to cathode, with $\lambda$ corresponding to the water content in the membrane in equilibrium with the humidity of the inlet gases. However, the anode-to-cathode water profile becomes highly nonlinear with increasing current density due to the generation of water at the cathode. This affects the parameters controlling the water transport (e.g., diffusivity and electro-osmotic drag), and the water content gradient becomes steeper closer to the cathode at
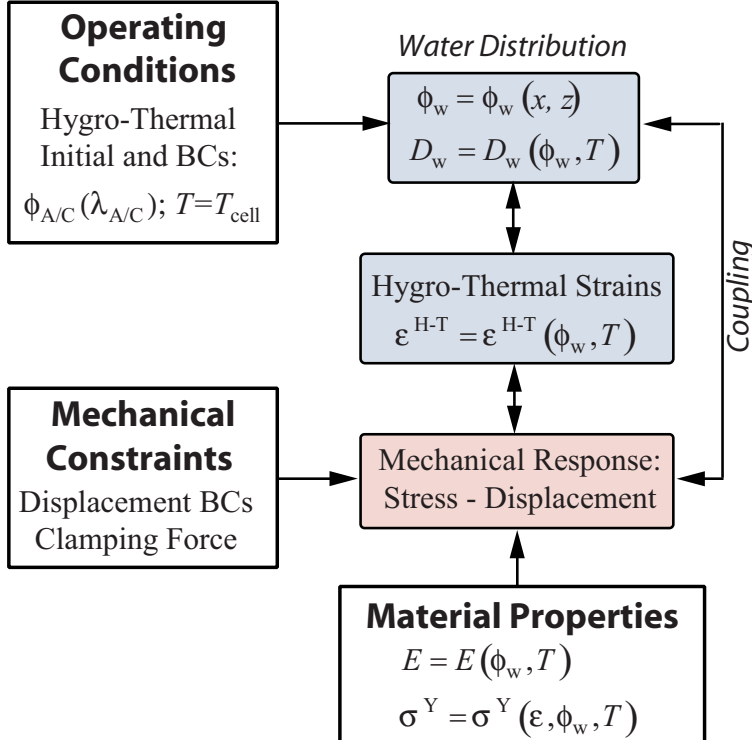

Figure 3. (Color online) Overview of the solution procedure for the coupled stress-diffusion numerical model.

very high current densities. ${ }^{43,45,49}$ Similar trends have been observed through numerical simulations even at a low temperature (down to $\left.-20^{\circ} \mathrm{C}\right){ }^{50}$

Solution procedure.-A schematic of the solution procedure is shown in Fig. 3. We use the commercial finite element package ABAQUS ${ }^{25}$ to solve the stress-displacement field for a given set of applied $(i)$ mechanical loads and (ii) hygrothermal loads. The applied mechanical loads are defined by the clamping boundary conditions, and the hygrothermal loads are defined by the uniform cell temperature $T_{\text {cell }}$ and the water volume fraction at the anode and cathode sides of the membrane, $\phi_{A}\left(\lambda_{A}\right)$ and $\phi_{C}\left(\lambda_{C}\right)$, respectively. Alternatively, the water volume fraction boundary conditions can be prescribed at the gas flow channels for OCV operation (Fig. 1). For a given set of loading conditions, the water volume fraction is determined at each node in the finite element (FE) model (where diffusion is allowed) through the numerical solution of the diffusion equation, and the temperature-dependent swelling strains given by Eq. 13 are implemented via the user subroutine UEXPAN. ${ }^{25}$ We used coupled temperature-displacement analysis ${ }^{25}$ with modifications that account for diffusion parameters to solve the problem. Using the constitutive relations and boundary conditions, the FE model determines the resulting stress and displacement fields, which, in turn, limit the swelling strains and, consequently, the water uptake. Thus, in this numerical model, water content and the stress/ displacement fields are coupled and solved simultaneously using the FE method. This modeling frame enables us to investigate the mechanical response during cell operation and the effect of the constraints on the water distribution. In the following, we discuss the results for several representative fuel cell operating conditions. Again, our intention is not to model any particular fuel cell but instead to show how the method can be used to study the effects of fuel cell parameters on the membrane stress and water distribution.

We first show the distribution of stresses and water for various loading cases and then present the maximum stresses in the membrane for various hydration loads. Later, we investigate the evolution of mechanical response during a single hydration-dehydration cycle and during some simplified fuel cell auto duty cycles.

\section{Results and Discussion}

Our previous studies ${ }^{13,17}$ showed that stresses in the plane of the membrane are higher than those in the through-the-thickness direc- 


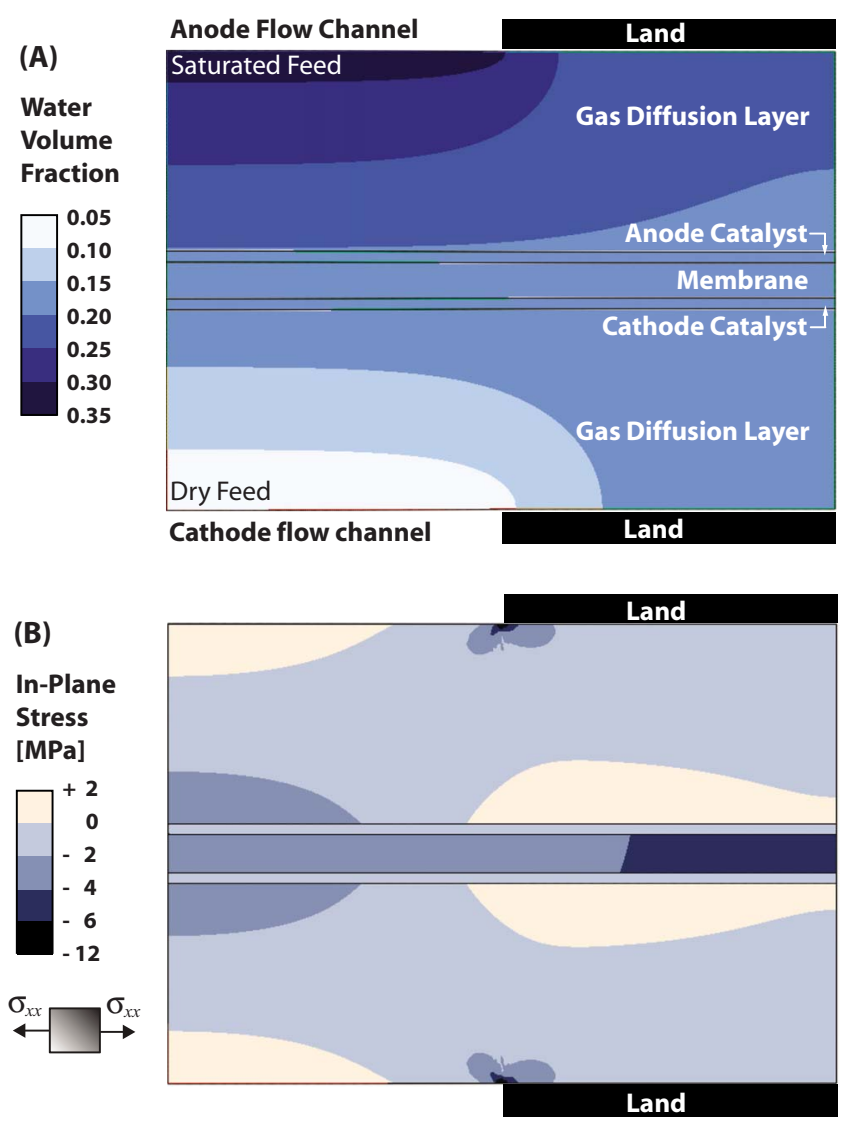

Figure 4. (Color online) Steady-state solution for (a) the water volume fraction and (b) the in-plane stresses $\sigma_{x x}$ in the MEA and GDL, with unreinforced PFSA membrane, for saturated $(\lambda=14)$ and dry $(\lambda=2)$ water vapors at the anode and cathode flow channels, respectively, at $T_{\text {cell }}=85^{\circ} \mathrm{C}$ for $P_{\mathrm{c}}=1 \mathrm{MPa}$ clamping pressure.

tion independent of the operating conditions. Therefore, we focus on the in-plane stresses $\sigma_{x x}$ to characterize the mechanical response.

Distribution of stress and water content with clamping effects. - The distribution of the in-plane stress $\sigma_{x x}$ and the water volume fraction $\phi_{\mathrm{w}}$ in the MEA and GDL, with the unreinforced PFSA membrane, is shown in Fig. 4 for $T_{\text {cell }}=85^{\circ} \mathrm{C}$ with saturated and dry inlet streams applied at the anode and cathode flow channels, respectively. This is a typical operating condition for automotive fuel cell applications. ${ }^{16}$ The figure demonstrates the simultaneous solutions for the concentration-driven diffusion of the water and corresponding swelling-induced in-plane stresses in the MEA for this set of boundary conditions. Even though the GDL is assumed not to swell (due to its porous structure), stresses in the GDL are generally much larger than those in the MEA due to the high Young's modulus of the carbon paper $(\sim 3 \mathrm{GPa})$ compared to that of the MEA (100-250 MPa). Moreover, stress concentrations at the intersection of the flow channel and bipolar plate are observed, indicating a potential failure site for the GDL.

To investigate the coupling between the displacement and water diffusion, we explore the influence of clamping load on the resulting stresses and water content in the MEA for the same operating condition described above. Cases of fixed clamping pressures $\left(P_{\mathrm{c}}\right.$ $=0.5,1.0$, and $4.0 \mathrm{MPa})$ and fixed clamping displacement $\left(\Delta_{\mathrm{c}}\right.$ $=0.0028 \mathrm{~mm}$ ) are considered. The distribution of the in-plane stresses developed at the anode side of the membrane during clamping are plotted in Fig. 5a from midchannel to the midland. Stresses further increase upon hydration and heating (Fig. 5b). We see in the figure that for low clamping pressures, the swelling-induced inplane stress is distributed uniformly along the membrane. With in-

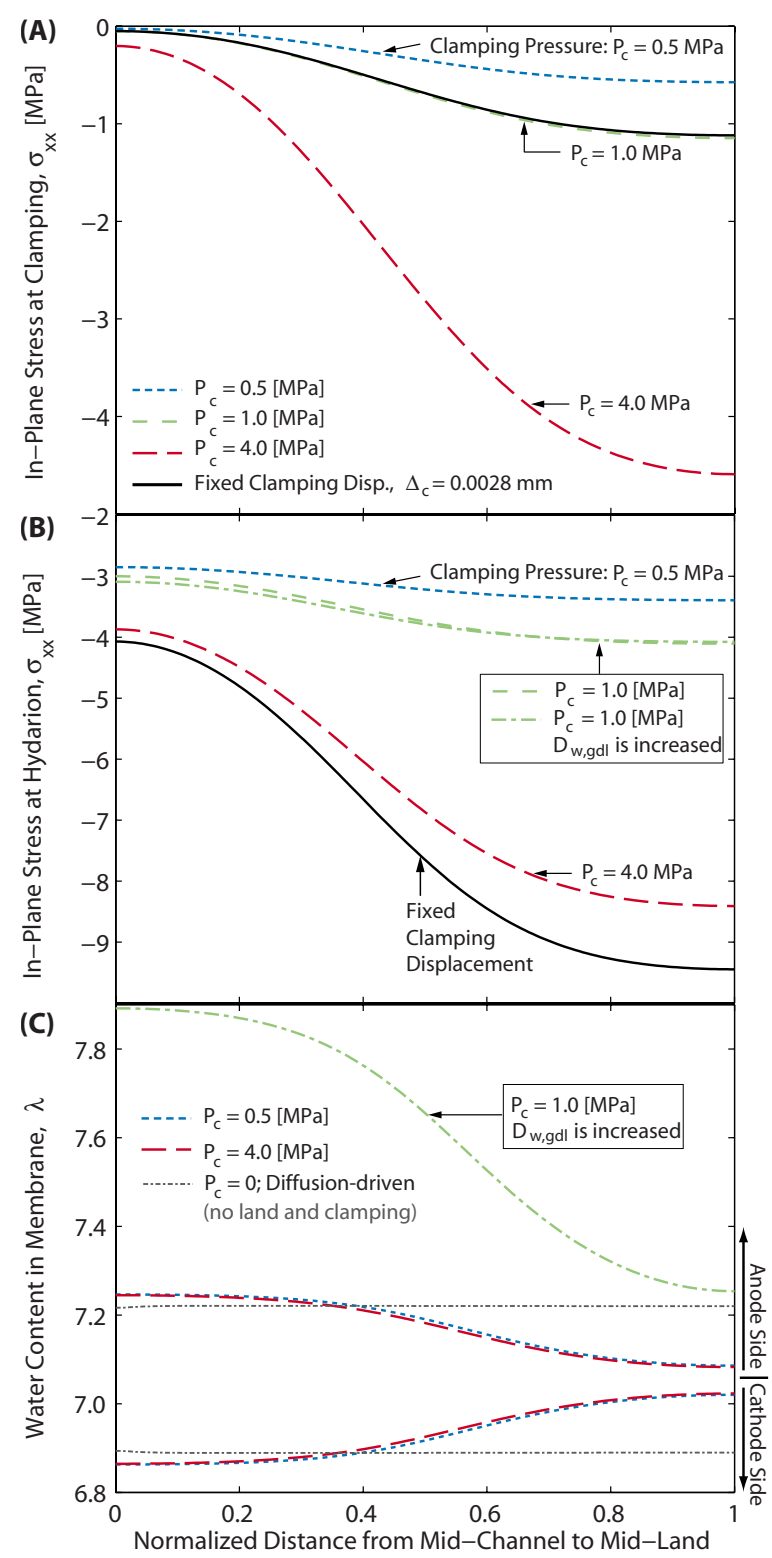

Figure 5. (Color online) Distribution of (a) in-plane stress $\sigma_{x x}$ after clamping and (b) that after hydration at the anode side of the membrane, and (c) water content $\lambda$ at the anode and cathode sides of the hydrated membrane as a function of normalized distance from midchannel to midland shown for clamping loads: Fixed clamping displacement, $\Delta_{\mathrm{c}}=0.0028 \mathrm{~mm}$, and fixed clamping pressure of $P_{\mathrm{c}}=0.5,1$, and $4 \mathrm{MPa}$. For comparison, results are shown (only at the anode side) for five-time-increased GDL diffusion $\left(D_{\mathrm{w}, \mathrm{GDL}}\right)$ at $P_{\mathrm{c}}=1 \mathrm{MPa}$. (Operating conditions for all cases are saturated and dry water vapors at the anode and cathode flow channels, respectively, at $T_{\text {cell }}=85^{\circ} \mathrm{C}$.)

creasing clamping pressure, however, the distribution becomes nonuniform, and the effect of the constraints is apparent under the lands. Similar results are obtained for the cathode side of the membrane (not shown for brevity). Moreover, the stress distribution after the initial clamping is the same (by definition) for both fixed displacement and fixed pressure $(1 \mathrm{MPa})$ cases. However, after hydration, fixed displacement clamping results in higher stresses than fixed pressure clamping (Fig. 5b), even though the water profiles are the same in both cases (Fig. 5c). This suggests that it is possible to optimize the clamping loads and other mechanical constraints without sacrificing the water transport.

The distribution of water content for several clamping cases is shown in Fig. 5c. The diffusion-driven water profile in the absence 
of any mechanical constraints is included in Fig. 5c for comparison. [The profile is developed as a result of the concentration difference between the anode (saturated) and cathode (dry) flow channels.] In Fig. 5, the constraints clearly affect the water distribution in the membrane when compared to a diffusion-driven water profile without clamping. The water content at the anode side of the land is less than that obtained for the diffusion-driven water profile due to a higher degree of constraint (e.g., bipolar plates). Thus, the water tends to accumulate through the cathode side of the land, which results in higher water content than that obtained for the diffusiondriven case.

Therefore, mechanical constraints applied to the MEA affect the uniformity of water transport. However, for the cases we have investigated so far, the water profile does not change significantly with further increase in the clamping pressure (from 0.5 to $4 \mathrm{MPa}$, Fig. $5 \mathrm{c}$ ), indicating that the effect of clamping on the water transport is relatively small. Consequently, for simplicity only, a fixed pressure clamping of $1 \mathrm{MPa}$ is discussed in the following.

Before proceeding, the diffusion coefficient of water in GDL, $D_{\mathrm{w}, \mathrm{GDL}}$ (discussed in the Model Definition section) might change depending on several factors, ${ }^{51}$ and the model is flexible enough to investigate the effects of these changes. For example, our investigations suggest that changing $D_{\mathrm{w}, \mathrm{GDL}}$ changes the water transport without changing the mechanical response. For example, when we increase the $D_{\mathrm{w}, \mathrm{GDL}}$ by a factor of 5 for the fixed clamping pressure $\left(P_{\mathrm{c}}=1 \mathrm{MPa}\right)$, the water profile in the membrane changes up to $10 \%$ (Fig. 5c), whereas the change in the stresses are small $(<1 \%)$ (Fig. 5b). It is believed that this is because of the balance between the two competing causes of water absorption (desorption) on the mechanical response; increasing (decreasing) water content (i) increases (decreases) the swelling strains and (ii) reduces (increases) the mechanical properties. Thus, the overall mechanical response of the membrane and GDL is almost independent of the diffusion coefficient in GDL within a reasonable range of diffusion coefficients.

Effect of cell operating conditions.- We now investigate the effect of anode dry-out (e.g., electro-osmotic drag) on mechanical response by adjusting the water content boundary conditions at the anode and cathode sides of the membrane. The distribution of the water content and corresponding compressive in-plane stresses in the hydrated MEA with the unreinforced PFSA membrane at $T_{\text {cell }}$ $=85^{\circ} \mathrm{C}$ are shown in Fig. $6 \mathrm{a}$ and $\mathrm{b}$ for $(i)$ uniform water profile through-the-thickness $\left(\lambda_{\mathrm{A}}=\lambda_{\mathrm{C}}=14\right)$ and (ii) anode dry-out $\left(\lambda_{\mathrm{A}}\right.$ $\left.=6, \lambda_{\mathrm{C}}=14\right)$. The nonlinear water profile through-the-thickness of the MEA with anode dry-out results in an in-plane stress gradient from the anode through the cathode. However, the stress gradient is always less than the water gradient. When the membrane absorbs water, the swelling increases, which tend to increase the stresses but, at the same time, Young's modulus decreases, which tends to lower the stresses.

The residual stresses after dehydration and cooling $\left(\lambda_{\mathrm{A}}=\lambda_{\mathrm{C}}\right.$ $=2, T_{\text {cell }}=25^{\circ} \mathrm{C}$ ) are depicted in Fig. $6 \mathrm{c}$ for the cases discussed above. Upon hydration, the regions with a large swelling strain (high water content) undergo plastic (permanent) deformation when the stresses exceed the yield strength at that temperature and water content. As a result, residual tensile stresses develop in these regions of the membrane upon dehydration. When the anode dries out due to electro-osmotic drag [case (ii)], the anode side of the MEA does not swell and therefore undergoes comparatively less plastic deformation. Consequently, the residual stresses are lower at the anode side for this case. This residual stress gradient is in contrast to the uniform $\lambda=14$ [case $(i)$ ], where the residual stresses are uniform. The stresses and the overall mechanical response at the cathode side of the membrane do not change significantly when the electro-osmotic effect is introduced because the water content here is assumed to remain at $\lambda_{\mathrm{C}}=14$ due to the constant generation of water during operation. In summary, the simulations suggest that anode dry-out reduces mechanical stresses and permanent deformation, which are

\section{(A) Water Content}

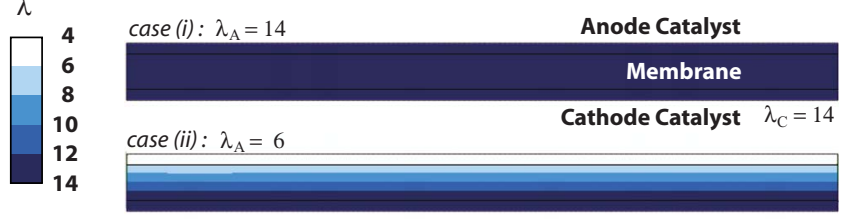

(B) Maximum In-Plane Stress in Hydrated State

[MPa] case (i): $\lambda_{\mathrm{A}}=14$

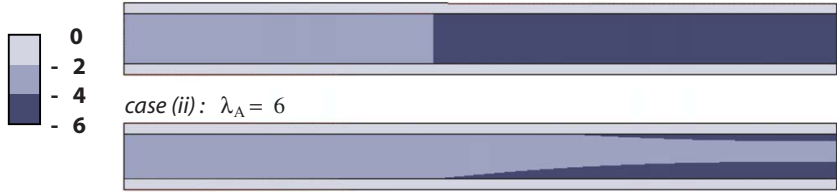

(C) Residual In-Plane Stress in After Dehydration

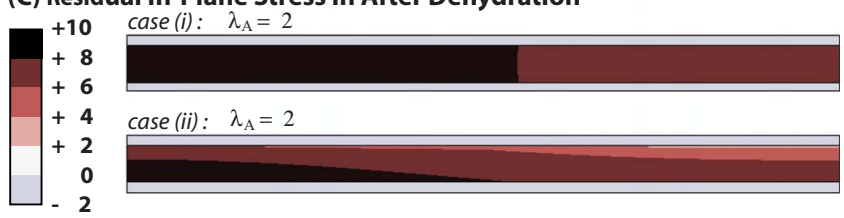

Figure 6. (Color online) Distribution of (a) water content $\lambda$ and (b) in-plane stresses $\sigma_{x x}$ in the hydrated state shown for uniformly $\left(\lambda_{\mathrm{A}}=\lambda_{\mathrm{C}}=14\right)$ and nonuniformly $\left(\lambda_{\mathrm{A}}=2, \lambda_{\mathrm{C}}=14\right)$ hydrated unreinforced PFSA membrane at $T_{\text {cell }}=85^{\circ} \mathrm{C}$. (c) Residual stresses after dehydration $\left(\lambda_{\mathrm{A}}=\lambda_{\mathrm{C}}=2, T_{\text {cell }}\right.$ $=25^{\circ} \mathrm{C}$ ) for both cases.

generally localized near the cathode side of the membrane. Localized degradation has been observed at the cathode side of the MEA, ${ }^{6,8,14,22}$ even though investigation of any relationship between the mechanical stresses and chemical degradation is beyond the scope of this study.

Maximum stresses in membrane for varying hydration loads.- Up to now, we have discussed the distribution of the stresses and water in the MEA for a set of fixed hydration boundary conditions at the anode and cathode. As mentioned earlier in the Model Definition section, the current density is not a variable in the model. Instead, to simulate various current density loads, we determine the swelling-induced stresses in the membrane for varying water contents at the anode $\lambda_{\mathrm{A}}$ and cathode $\lambda_{\mathrm{C}}$ to simulate a range of cell operating conditions. We consider a wide range of anode/ cathode water contents for this parametric study, even though some of the selected water contents may not be realized in actual fuel cell operations. The maximum in-plane stresses in the midchannel of the unreinforced PFSA membrane are plotted at the anode (Fig. 7a) and cathode (Fig. 7b) sides for selected water content conditions. We include cathode water contents of 18 and 22 in this investigation, corresponding to the vapor-to-liquid transition regime in the membrane, ${ }^{41,45,52}$ by using the properties of the membrane in liquid water from our previous work.

Figure 7 suggests that the compressive in-plane stresses in the membrane increase with increasing water content and reach a maximum in liquid water $\left(\lambda_{C}=22\right)$ due to the large swelling strains at this water content level (Fig. 2). Therefore, low humidity operation appears to be desirable for reducing mechanical stresses. Stresses at the anode side of the membrane decrease with anode dry-out (Fig. $7 a)$, which can be associated with an increase in current density during cell operation. Consequently, under OCV operation, the stresses in the MEA are uniform from the anode to the cathode and are strongly dependent on the inlet humidity (or the equivalent water content in the membrane), whereas in a cell operating under large current densities, stresses at the anode side become much smaller than the stresses at the cathode side. 
(A) Stresses in Hydrated Membrane (Anode Side)

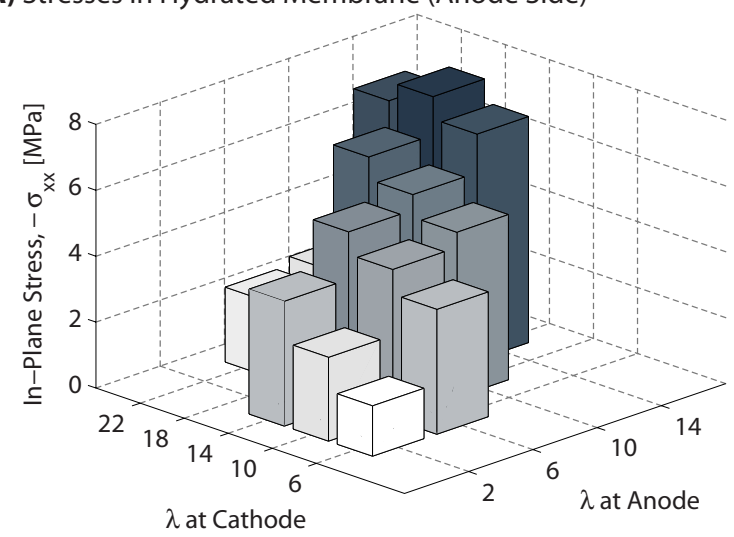

(B) Stresses in Hydrated Membrane (Cathode Side)

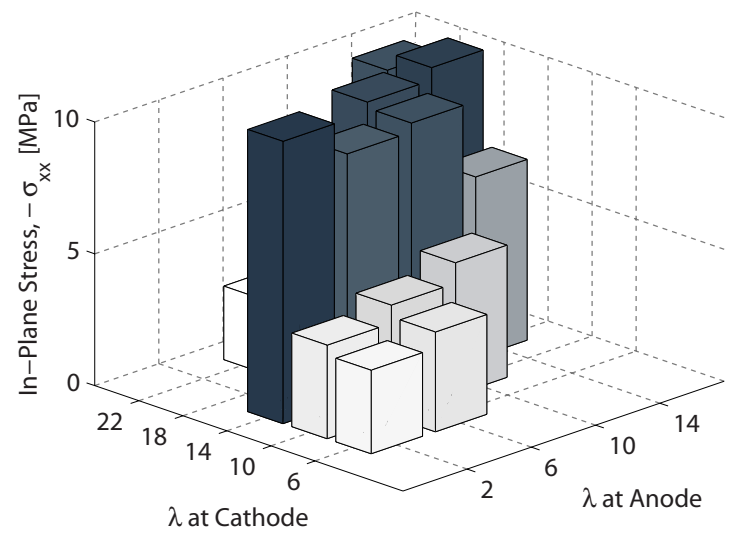

Figure 7. (Color online) In-plane stresses $\sigma_{x x}$ at the (a) anode and (b) cathode sides of the unreinforced PFSA membrane hydrated by applying various anode/cathode water boundary conditions at $T_{\text {cell }}=85^{\circ} \mathrm{C}$, shown under the middle of channels (see Fig. 4 for the exact position).

Evolution of stresses during a single hydration-dehydration cycle.- In this section, we simulate a single simplified operating cycle, including startup, steady-state operation, and shutdown. This is achieved by applying a hygrothermal load to saturate the initially dry MEA, then by drying and rehydrating the anode side (while the cathode is kept saturated), and followed by dehydration back to the initial state. The evolution of the water content at the anode and cathode and the uniform temperature in the MEA during this cycle are shown in Fig. 8a and b. After the initial hygrothermal load, the water content at the anode is alternately set to $\lambda_{\mathrm{A}}=10,6$, and 2 (corresponding to low, medium, and high anode dry-outs, respectively) to examine the effect of the anode dry-out on the mechanical response during subsequent loads. The results show that even though the in-plane stresses at the anode side are affected by the anode water content during dry-out, the residual stresses after dehydration (at room temperature) are mostly independent of the water content level during loading (Fig. 8c). The plastic strains accumulated during this cycle are not that different for the cases examined (Fig. 8d). Because the magnitude of the residual stress is related to the accumulated plastic strain, regions with a similar plastic deformation history exhibit similar residual tensile stresses.

Stresses in a reinforced membrane are similar to those in the unreinforced PFSA membrane for the high anode dry-out cell operation $\left(\lambda_{\mathrm{A}}=2\right)$ (Fig. 8c and d). Recall that both membranes are assumed to have the same water uptake at a given humidity, but the in-plane swelling of the reinforced membranes is much lower than that of an isotropically swollen PFSA membrane. Thus, the thickness swelling of the reinforced membrane is larger than that of

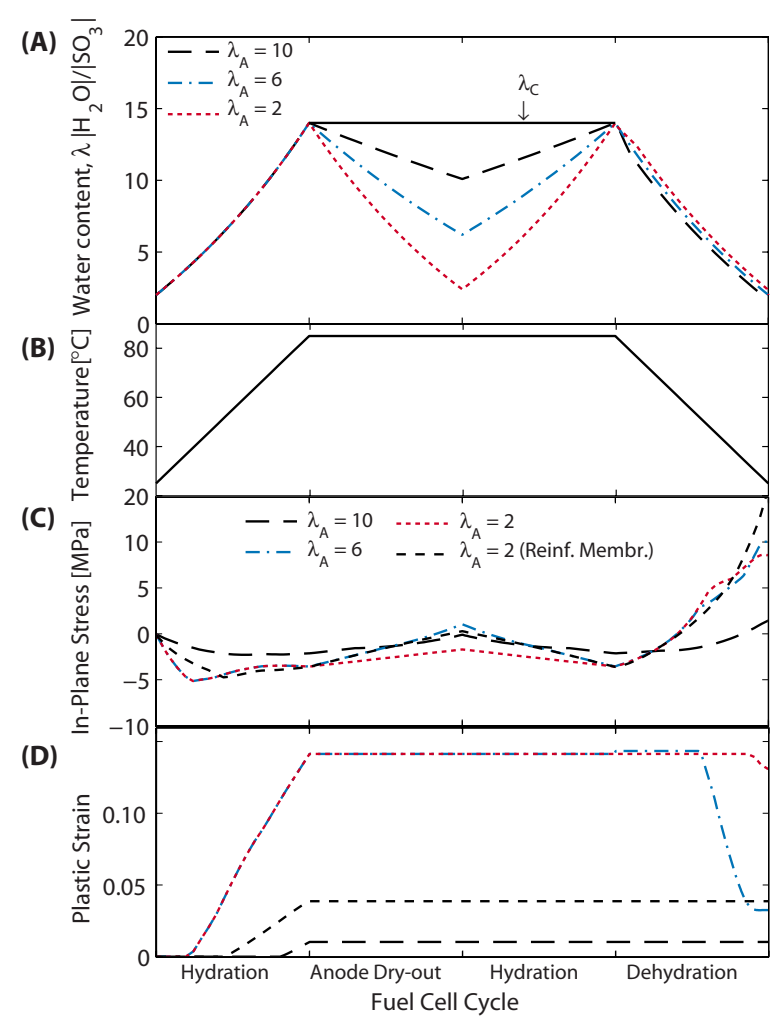

Figure 8. (Color online) Evolution of (a) water content, (b) temperature, (c) in-plane stresses $\sigma_{x x}$, and (d) magnitude of plastic strains at the anode side of the membrane during one single-cell cycle with varying levels of anode dry-out. Results for the reinforced membrane are included for comparison only for high anode dry-out.

PFSA membranes, resulting in larger out-of-plane stresses especially under the lands (not shown). However, the reinforced membrane exhibits less plastic (permanent) deformation compared to unreinforced PFSA (Fig. 8d). Thus, reinforcement of the membranes may improve the durability of an MEA. We previously showed that reinforced membranes experience lower stresses under accelerated RH cycling, indicating a significant reduction in fatigue loading. ${ }^{18}$ The current findings also agree with the fuel cell test results, which suggest that low in-plane swelling of the membranes increases the operational lifetime.

Mechanical response at subzero temperatures.- Investigation into fuel cell operation and durability in cold environments is of great interest due to the need for a subzero startup. ${ }^{1,53}$ However, studies on durability in fuel cells during subfreezing temperature operations (e.g., during freeze/thaw cycles) are limited, ${ }^{27,54-57}$ and the effects of the freeze/thaw cycling and heating/cooling rate on degradation mechanisms are still not well understood. ${ }^{53}$ Here, we examine how cooling to subzero temperatures may affect the mechanical response during the subsequent hydration by incorporating our preliminary data ${ }^{58}$ for the material properties of unreinforced PFSA membranes obtained at subzero temperatures in the humidity range of 30-70\% RH. Therefore, we simulate a simplified, uniform hygrothermal freeze-thaw cycle within this humidity range (Fig. 9A). We also assume that Eq. 13 for swelling strain increments can be used at subzero temperatures, which agrees with our ongoing experiments. From the figure, we observed an increase in the magnitude of the in-plane stresses when the membrane is cooled down to $-20^{\circ} \mathrm{C}$ instead of $+25^{\circ} \mathrm{C}$ (Fig. 9B). However, the membrane cycled in a subzero environment $\left(-20\right.$ to $\left.85^{\circ} \mathrm{C}\right)$ undergoes similar plastic deformation and consequently exhibits similar residual stresses compared to that cycled in a warmer environment $(+25$ to $85^{\circ} \mathrm{C}$ ). During cycling in a subzero environment, the maximum ten- 


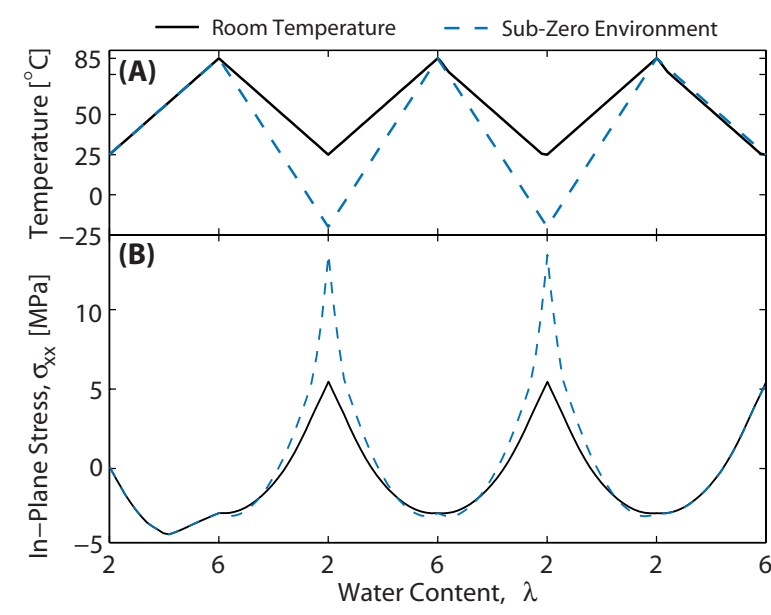

Figure 9. (Color online) Evolution of the (A) water content $\lambda$ and (B) in-plane stress $\sigma_{x x}$ in an unreinforced PFSA membrane subjected to hygrothermal loading-unloading cycles from 25 to $85^{\circ} \mathrm{C}$ and from -20 to $85^{\circ} \mathrm{C}$ (subzero environment).

sile stresses are much higher even though they are subject to similar strain values. This can be attributed to the higher Young's modulus of the material at colder temperatures, which leads to higher stresses for the same strain. Even though in this model higher strength results in less plastic deformation, this does not eliminate the possibility of brittle failure, the investigation of which requires alternative models and is therefore left for future study. Lastly, the stresses under the lands follow a very similar trend to that under the channel (Fig. 9B) except that the peak stresses under the land are 40-50\% lower. These high residual tensile stresses under the channels might be associated with the failures observed in the MEA and/or GDL during freeze/thaw cycling. ${ }^{54,57}$

Fuel cell auto duty cycle.- Lastly, we simulate a continuous fuel cell duty cycle for an unreinforced PFSA membrane with varying current densities by applying various hydration loads at the anode and cathode, as shown in Fig. 10a. This cycle is inspired from the test protocol developed to monitor the long-term performance of fuel cells in vehicular applications. ${ }^{53,59}$ After the initial hygrothermal load, the anode water content is varied between $\lambda_{\mathrm{A}}=2-14$, whereas the cathode water content is kept constant at $\lambda_{C}=14$. Consequently, the anode side of the membrane experiences sudden changes in in-plane stresses (Fig. 10b). However, the history of plastic deformation is similar for both sides of the membrane (Fig. 10c). This can be attributed to the interplay between the increasing yield strength and Young's modulus, along with decreasing swelling at lower water contents. For example, the change in Young's modulus during this cycle is shown in (Fig. 10d). ${ }^{33}$ An increase (or decrease) in the water content results in a decrease (or increase) in Young's modulus. Therefore, the water gradient in the membrane leads to a variation in material properties through the membrane. Even though the actual constitute behavior is highly nonlinear (as explained in the Model Definition section), it is believed that this phenomenon is critical to the understanding of the relationship between the water transport and stress-dominated damage mechanisms.

\section{Conclusions}

In this work, we investigated the mechanical response and swelling behavior of the MEA through numerical simulations of various fuel cell operating conditions. We introduced a numerical model that couples (and therefore simultaneously solves) stress displacement and water diffusion fields. Material properties for the membrane and electrodes are incorporated into the model as empirical functions of water content and temperature based on our previous and ongoing experimental work.

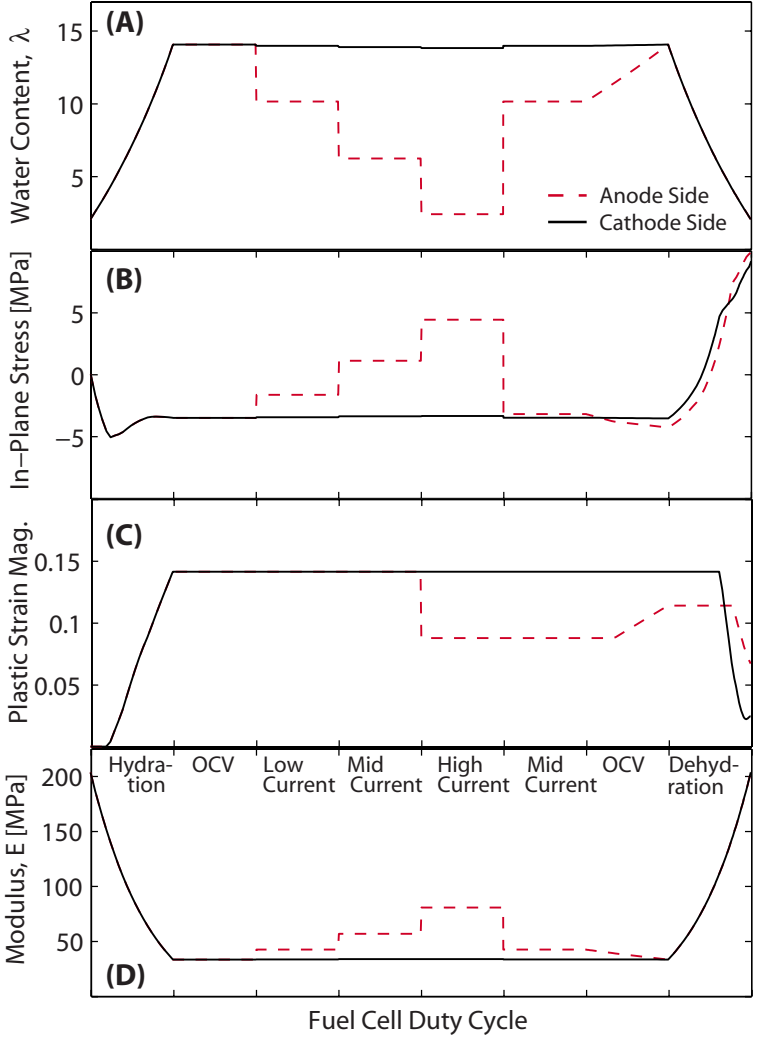

Figure 10. (Color online) (a) Variation in applied water content at anode/ cathode of an unreinforced PFSA membrane to simulate a simplified fuel cell duty cycle and resulting (b) in-plane stresses $\sigma_{x x}$ and (c) magnitude of the plastic strain. (d) Young's modulus corresponding to the applied water content is calculated using the model in Ref. 33.

The results show that swelling plays a key role in the mechanical response of the MEA during fuel cell operation by inducing stresses in the MEA. We also show that the degree of mechanical constraints applied to the MEA may limit the swelling of the membrane. However, the change in water content $\lambda$ due to these effects is negligible for the values considered in this study. The stresses in the MEA increase with increases in the $(i)$ stiffness of the GDL, (ii) stiffness of the bipolar plate, (iii) clamping load, and (iv) thickness of the GDL.

Improvement in the transport properties (e.g., diffusion coefficient of water in cell components) is generally not detrimental to the mechanical response due to the interplay between the swelling and mechanical properties (e.g., stiffness). Water absorption in the membrane, while increasing the swelling, reduces the mechanical properties, and the net effect on the mechanical stresses is less pronounced.

The water content (or humidity) has a stronger effect on the mechanical response than temperature because swelling due to water uptake is much larger than thermal expansion. Also, for a given set of operating conditions, reinforced membranes exhibit less plastic deformation than unreinforced membranes primarily due to the lower in-plane swelling, even though the total water uptake is almost the same.

If electro-osmotic drag is present, the stresses and plastic strain are generally localized at the cathode side of the membrane. However, the stress gradient is always less severe than the water gradient because water absorption increases the swelling (and tends to increase the stresses) but reduces the mechanical properties (in favor of lower stresses). No significant change in the mechanical response is observed for a membrane subjected to a single freeze/thaw cycle between hydration-dehydration cycles at an elevated temperature. 
These results indicate that membrane lifetime may be governed by, in addition to chemical degradation, mechanical damage because material loss during cell operation might also be triggered and eventually dominated by the stresses and permanent deformation. However, the relationship between the mechanical stresses and chemical degradation and/or material thinning must be investigated further. For example, the effect of the mechanical constraint and the associated stresses on the rate of chemical degradation in the MEA and the mechanics of the crack initiation at potential failure sites are of critical importance. We believe that this study explains some of the mechanical aspects of the durability of PEMFC and provides insight for developing effective strategies to improve durability in fuel cells.

\section{Acknowledgments}

The funding for this work was provided by the Federal Highway Administration, W.L. Gore and Associates, the State of Delaware Development Office, and the U.S. Department of Energy Hydrogen Program.

\section{List of Symbols}

E Young's modulus, $\mathrm{MPa}$

EW equivalent weight of the PFSA membrane, $\mathrm{g} / \mathrm{mol}$

$D_{\mathrm{w}, \mathrm{M}}$ diffusion coefficient of water in medium $\mathrm{M}, \mathrm{cm}^{2} / \mathrm{s}$

$T$ temperature, ${ }^{\circ} \mathrm{C}$

Greek

$\alpha \quad$ linear coefficient of thermal expansion, $C^{-1}$

$\varepsilon_{i j}$ components of the true strain tensor

$\varepsilon_{\mathrm{V}}$ volumetric strain (natural logarithm of volume change)

$\begin{array}{cl}\varepsilon_{\mathrm{V}} & \text { volumetric strain (natural logarithm of volu } \\ \lambda & \text { water content in the membrane }\left(\mathrm{H}_{2} \mathrm{O} / \mathrm{SO}_{3}^{-}\right)\end{array}$

$\xi_{i}$ anisotropy ratio of swelling in the $i$-direction: ratio of the dimensional change in the $i$-direction of the membrane to the total volume change of the membrane.

$\sigma_{i j}$ components of the true stress tensor, $\mathrm{MPa}$

$v$ Poisson's ratio

$\phi_{\mathrm{p}}\left(\phi_{\mathrm{w}}\right)$ polymer (water) volume fraction

Subscripts

$$
\begin{aligned}
& \text { A anode (side of the membrane) } \\
& \text { C cathode (side of the membrane) } \\
& \text { P polymer } \\
& \text { W water }
\end{aligned}
$$

Superscripts

$$
\begin{aligned}
\text { el } & \text { elastic } \\
\text { pl } & \text { plastic } \\
\text { sw } & \text { swelling } \\
\text { th } & \text { thermal }
\end{aligned}
$$

\section{References}

1. N. L. Garland and J. P. Kopasz, J. Power Sources, 172, 94 (2007)

2. V. A. Sethuraman, J. W. Weidner, A. T. Haug, and L. V. Protsailo, J. Electrochem. Soc., 155, B119 (2008).

3. J. Healy, C. Hayden, T. Xie, K. Olson, R. Waldo, A. Brundage, H. Gasteiger, and J. Abbott, Fuel Cells, 5, 302 (2005).

4. D. E. Curtin, R. D. Lousenberg, T. J. Henry, P. C. Tangeman, and M. E. Tisack, J. Power Sources, 131, 41 (2004)

5. E. Endoh, S. Terazono, H. Widjaja, and Y. Takimoto, Electrochem. Solid-State Lett., 7, A209 (2004).

6. W. Liu and M. Crum, ECS Trans., 3(1), 531 (2006).

7. J. Xie, D. L. Wood III, D. M. Wayne, T. A. Zawodzinski, P. Atanassov, and R. L. Borup, J. Electrochem. Soc., 152, A104 (2005).

8. M. Crum and W. Liu, ECS Trans., 3(1), 541 (2006)

9. X. Huang, R. Solasi, Y. Zou, M. Feshler, K. Reifsnider, D. Condit, S. Burlatsky, and T. Madden, J. Polym. Sci., Part B: Polym. Phys., 44, 2346 (2006).

10. S. Kundu, M. W. Fowler, L. C. Simon, and S. Grot, J. Power Sources, 157, 650 (2006).

11. V. Stanic and M. Hoberecht, Meet. Abstr., 802, 1123 (2006).

12. J. Xie, D. L. Wood III, K. L. More, P. Atanassov, and R. L. Borup, J. Electrochem. Soc, 152, A1011 (2005).

13. A. Kusoglu, A. M. Karlsson, M. H. Santare, S. Cleghorn, and W. B. Johnson, J.
Power Sources, 161, 987 (2006).

14. S. Stucki, G. G. Scherer, S. Schlagowski, and E. Fischer, J. Appl. Electrochem., 28, 1041 (1998).

15. M. F. Mathias, R. Makharia, H. A. Gasteiger, J. J. Conley, T. J. Fuller, C. J. Gittleman, S. S. Kocha, D. P. Miller, C. K. Mittelsteadt, T. Xie, et al., Electrochem. Soc. Interface, 14, 24 (2005).

16. U. Beuscher, S. J. C. Cleghorn, and W. B. Johnson, Int. J. Energy Res., 29, 1103 (2005).

17. Y. Tang, M. H. Santare, A. M. Karlsson, S. Cleghorn, and W. B. Johnson, J. Fuel Cell Sci. Technol., 3, 119 (2006).

18. Y. Tang, A. Kusoglu, A. M. Karlsson, M. H. Santare, S. Cleghorn, and W. B. Johnson, J. Power Sources, 175, 817 (2008).

19. A. Kusoglu, A. M. Karlsson, M. H. Santare, S. Cleghorn, and W. B. Johnson, J. Power Sources, 170, 345 (2007).

20. R. Solasi, Y. Zou, X. Huang, K. Reifsnider, and D. Condit, J. Power Sources, 167, 366 (2007).

21. S. Cleghorn, J. Kolde, and W. Liu, in Handbook of Fuel Cells: Fundamentals, Technology and Applications, V. Wolf, L. Arnold, and G. Hubert, Editors, John Wiley \& Sons, New York (2003).

22. S. J. C. Cleghorn, D. K. Mayfield, D. A. Moore, J. C. Moore, G. Rusch, T. W. Sherman, N. T. Sisofo, and U. Beuscher, J. Power Sources, 158, 446 (2006).

23. W. Liu, K. Ruth, and G. Rusch, J. New Mater. Electrochem. Syst., 4, 227 (2001).

24. J. A. Kolde, B. Bahar, M. S. Wilson, T. A. Zawodzinski, and S. Gottesfeld, in Proceedings of the First International Symposium on Proton Conducting Membrane Fuel Cells, PV 95-23, p. 193, The Electrochemical Society Proceedings Series, Pennington, NJ (1995).

25. ABAQUS, Documentation and User's Manual, ABAQUS Inc. (2003).

26. J. Spendelow, R. Mukundan, J. Davey, T. Rockward, D. S. Hussey, D. Jacobson, M. Arif, and R. L. Borup, ECS Trans., 16(2), 1345 (2008).

27. R. C. McDonald, C. K. Mittelsteadt, and E. L. Thompson, Fuel Cells, 4, 208 (2004).

28. A. P. Boresi and K. P. Chong, Elasticity in Engineering Mechanics, p. 277, John Wiley \& Sons, New York (2000).

29. R. Hill, The Mathematical Theory of Plasticity, Clarendon, Oxford (1950).

30. SGL, Product Information for Sigracet GDL, SGL Carbon Group.

31. Y. H. Lai, P. A. Rapaport, C. Ji, and V. Kumar, J. Power Sources, 184, 120 (2008)

32. Y. Tang, A. M. Karlsson, M. H. Santare, M. Gilbert, S. Cleghorn, and W. B. Johnson, Mater. Sci. Eng., A, 425, 297 (2006).

33. A. Kusoglu, M. H. Santare, A. M. Karlsson, S. Cleghorn, and W. B. Johnson, J. Polym. Sci., Part B: Polym. Phys., 46, 2404 (2008).

34. A. Kusoglu, Y. Tang, M. H. Santare, A. M. Karlsson, S. Cleghorn, and W. B. Johnson, J. Fuel Cell Sci. Technol., 6, 011012 (2009).

35. A. Kusoglu, Y. Tang, M. Lugo, A. M. Karlsson, M. H. Santare, S. Cleghorn, and W. B. Johnson, J. Power Sources, 195, 483 (2010).

36. M. Griffith and T. Schmiedel, Meet. Abstr., 802, 1030 (2008).

37. T. E. Springer, T. A. Zawodzinski, and S. Gottesfeld, J. Electrochem. Soc., 138 2334 (1991).

38. T. Thampan, S. Malhotra, H. Tang, and R. Datta, J. Electrochem. Soc., 147, 3242 (2000).

39. E. L. Thompson, J. Jorne, W. B. Gu, and H. A. Gasteiger, J. Electrochem. Soc., 155, B625 (2008)

40. A. E. T. Takamatsu, J. Appl. Polym. Sci., 24, 2221 (1979).

41. A. Z. Weber and J. Newman, J. Electrochem. Soc., 151, A311 (2004).

42. H. C. Ju, C. Y. Wang, S. Cleghorn, and U. Beuscher, J. Electrochem. Soc., 152, A1645 (2005).

43. A. A. Kulikovsky, J. Electrochem. Soc, 150, A1432 (2003).

44. D. A. G. Bruggeman, Ann. Phys. (Leipzig), 24, 636 (1935).

45. P. P. Mukherjee, T. Springer, R. Mukundan, D. S. Hussey, D. Jacobson, M. Arif, and R. L. Borup, ECS Trans., 16(2), 1027 (2008).

46. T. Okada, G. Xie, and M. Meeg, Electrochim. Acta, 43, 2141 (1998).

47. A. Z. Weber and J. Newman, J. Electrochem. Soc., 151, A326 (2004).

48. R. J. Bellows, M. Y. Lin, M. Arif, A. K. Thompson, and D. Jacobson, J. Electrochem. Soc., 146, 1099 (1999).

49. F. N. Büchi and G. G. Scherer, J. Electrochem. Soc., 148, A183 (2001).

50. E. L. Thompson, J. Jorne, W. B. Gu, and H. A. Gasteiger, J. Electrochem. Soc., 155, B887 (2008).

51. D. R. Baker, D. A. Caulk, K. C. Neyerlin, and M. W. Murphy, J. Electrochem. Soc., 156, B991 (2009).

52. A. Z. Weber and J. Newman, J. Electrochem. Soc., 150, A1008 (2003).

53. R. Borup, J. Meyers, B. Pivovar, Y. S. Kim, R. Mukundan, N. Garland, D. Myers, M. Wilson, F. Garzon, D. Wood, et al., Chem. Rev. (Washington, D.C.), 107, 3904 (2007).

54. R. Mukundan, J. Davey, R. Lujan, J. Spendelow, Y. S. Kim, D. S. Hussey, D. Jacobson, M. Arif, and R. L. Borup, ECS Trans., 16(2), 1939 (2008).

55. S. Kim and M. M. Mench, J. Power Sources, 174, 206 (2007).

56. M. S. Wilson, J. A. Valerio, and S. Gottesfeld, Electrochim. Acta, 40, 355 (1995)

57. R. Mukundan, S. K. Yu, F. Garzon, and B. Pivovar, ECS Trans., 1(8) 403 (2005)

58. A. Kusoglu, A. Karlsson, and M. Santare, Polymer, 51, 1457 (2010).

59. R. L. Borup, J. R. Davey, F. H. Garzon, D. L. Wood, and M. A. Inbody, J. Power Sources, 163, 76 (2006). 